\title{
Why DOMA is unconstitutional, beyond the traditional views of same sex relationships
}

\author{
Mary E. Sabatini • Don S. Dizon
}

Received: 1 May 2013 /Accepted: 17 May 2013 / Published online: 31 May 2013

(C) Springer Science+Business Media New York 2013

The debate regarding the Defense of Marriage Act (DOMA) is centered on issues of sexuality. Yet, surprisingly within the statute there are no definitions for "man" and "woman." These terms may seem self-evident; however, we would argue that it is not always clear.

How would DOMA impact the marriages of two couples in which the gender of one of the spouses is in question? For example two couples present due to infertility: During the evaluations, the wife of couple number one is discovered to be genetically male. She has a $46, \mathrm{XY}$ karyotpe and undescended testicles, consistent with the diagnosis of androgen insensitivity. The work-up of couple number two shows that the male partner has severe oligospermia and genetic analysis reveals he has genetic mosaicism (46, XY and 45, X0).

In both cases, these couples are "legally" married. Does knowledge of their genetics negate their marriages under DOMA? Does this knowledge then expose those of us who treat patients with infertility in legal jeopardy? We assume that reasonable people would conclude that because the individuals in the above examples define themselves and live their lives as "male" or "female," their marriages are

\section{E. Sabatini $(\bowtie)$}

Division of Reproductive Endocrinology and Infertility,

Vincent Memorial Department of Obstetrics and Gynecology,

Massachusetts General Hospital, Boston, MA, USA

e-mail: msabatini@partners.org

\section{S. Dizon}

Gillette Center for Gynecological Oncology, Oncology Sexual Health Clinic, Massachusetts General Hospital Cancer Center, Boston, MA, USA

e-mail: ddizon@partners.org legally valid and should be protected. One could also imagine, however, that that knowledge of the genetics could put the physician in a compromising situation should genetic information be known by someone with political motivations against one or both members of the couple. For example, could the physician's knowledge result in criminal prosecution for the physician by an overzealous prosecutor for aiding tax evasion?

To date, the debate about DOMA has assumed a common definition of gender while almost exclusively focusing on issues of homosexuality versus heterosexuality. But, in truth, DOMA has broader implications for medicine and for society. As these cases illustrate, the definition of "man" and "woman" is actually quite complex but is also relevant to the discussion of DOMA.

The responsibility of government is to preserve the liberties of every citizen and enforce what is universally acceptable for our society. The Founding Fathers could not have anticipated all of the medical knowledge that has blossomed since the Constitution was written; they could never have anticipated the medical information obtained about the couples above, just as we can not anticipate the things we may learn in the future. Our constitution protects EVERY citizen of the United States. Yet, DOMA imposes disparities in marriage protections to those individuals who fall outside of the "normal" range.

Even if there was but a single person who was not easy to define as "man" or "woman," DOMA would be unconstitutional. Regardless of genetics, gender, or sexuality, each person should be free to choose another consenting adult to whom they can be bound in a legal relationship called marriage. 